\title{
Recurrent macroscopic haematuria due to bladder blood vessels after exercise induced haematuria
}

\section{P Lüthje, I Nurmi}

Br J Sports Med 2004;38:e4 (http://www.bjsportmed.com/cgi/content/full/38/3/e4). doi: 10.1136/bjsm.2003.007278

The case is reported of exercise induced asymptomatic macroscopic haematuria, which became recurrent haematuria no longer induced by exercise. The cause, diagnosis, and management are discussed. An overview of the potential causes of sport related haematuria is presented.

E xercise related asymptomatic macroscopic haematuria has been noted in runners. The prevalence of running related haematuria is about $20-25 \%$ for distances of $21-$ $90 \mathrm{~km} .{ }^{1-3}$ This phenomenon also occurs in those who run shorter distances $(>10 \mathrm{~km}) .{ }^{4}$ In most cases, the haematuria is microscopic and possibly related to renal ischaemia. ${ }^{5}$ Less common, lower urinary tract bleeding is associated with higher counts of urinary red cells. ${ }^{5}$

\section{CASE REPORT}

A previously healthy 58 year old white man consulted the clinic in June 2001 because of exercise related macroscopic haematuria that occurred immediately after a one hour jog. He had taken part in a $10 \mathrm{~km}$ competition annually for 15 years each September and had been training throughout the year.

The gross haematuria lasted 12 hours. Cystoscopy was conducted next day. Some small adherent clots were seen on the posterior wall of the bladder and these were biopsied. The histology was normal. The cystoscopy showed mild prostatic occlusive disease, with large vessels on the middle lobus of the prostate and many crossing but normal vessels in the posterior wall of the bladder. There was no haemorrhagic telangiectasis. Endoscopically the bladder and anterior urethra were normal.

Renal ultrasonography, abdominal ultrasonography of the prostate, and excretory urography all showed normal results. The prostate volume was about $25 \mathrm{ml}$.

Full blood count, prothrombin time, partial thromboplastin time, a platelet count, bleeding time, creatinine concentration, and prostate specific antigen (PSA) were measured, and were normal. Urine samples were sent for cytology. No malignant cells were detected. The blood pressure of the patient was normal $(115 / 80 \mathrm{~mm} \mathrm{Hg})$. He had been taking $100 \mathrm{mg}$ aspirin a day for a year. This treatment was stopped. The diagnosis was exercise related macroscopic haematuria. The morphology of the red cells in the urine was not studied.

One month later, the macroscopic haematuria recurred after the patient had started running again, and some weeks later the patient noticed macroscopic haematuria that was not induced by exercise but occurred during the normal daily routine. Renal computed tomography was performed, with normal results. Cystoscopy was carried out again and a retrograde pyelography. There were many suburethral prostatic blood vessels, which could be the reason for haematuria. Otherwise the findings were normal. Treatment with finasteride ( $5 \mathrm{mg} /$ day) was started. No malignant cells were found in urine samples.

Because the recurrent haematuria persisted, a further cystoscopy was performed in November; the vessels in the prostatic urethra were electrocoagulated. There were a few big crossing but otherwise normal vessels on the posterior wall of the bladder. The bladder was otherwise endoscopically normal. Rectal ultrasonography showed a normal prostate (size $27-28 \mathrm{ml}$ ). Samples of urine from both ureters were examined, but there were no blood cells or malignant cells.

Despite the daily dose of finasteride, the recurrent haematuria did not stop, and, in March 2002, a fourth cystoscopy was performed. The large, visible crossing vessels on the posterior wall of the bladder were electrocoagulated. Before this treatment, magnetic resonance imaging of the urinary tract and prostate was performed; both were normal.

Three to four weeks later, the macroscopic haematuria stopped. The patient finished taking finasteride one month later. Since then, the urine has been examined for red blood cells on several occasions and found to be normal. The patient began running again in May 2002, and took part in the annual $10 \mathrm{~km}$ competition in September 2002, with no recurrence of haematuria.

\section{DISCUSSION}

In this case, the gross haematuria started after strenuous exercise. Typically, it began after a one hour run, and recurred after one month after a $10 \mathrm{~km}$ run. Later it occurred repeatedly during normal daily activity.

Recurrent haematuria is a well documented symptom of benign prostatic hyperplasia. In a large retrospective study of patients who underwent transurethral prostatic resection, haematuria was an indication for surgery in $12 \% .^{6}$ Although the reason for bleeding with benign prostatic hyperplasia is not fully understood, it is probably related to increased vascularity in the prostate.

According to Foley et al, ${ }^{8}$ haematuria due to benign prostatic hyperplasia is effectively suppressed by finasteride, a $5 \alpha$-reductase inhibitor that prevents the conversion of testosterone into dihydrotestosterone. In that study, the finasteride group ( $5 \mathrm{mg} /$ day) were treated for 12 months, and haematuria resolved within four weeks in all the patients. ${ }^{8}$ Further studies have confirmed its effect in limiting haematuria. ${ }^{9} 10$

In this case, the patient took $5 \mathrm{mg}$ finasteride a day, but the recurrent gross haematuria persisted. After four months, the suburethral prostatic vessels were electrocoagulated. As the haematuria persisted, the origin had to be something other than the prostate. The problem did not disappear until the crossing but otherwise normal vessels found on the posterior wall of the bladder were electrocoagulated.

We searched Medline from 1966 to July 2003 (keywords: haematuria and bladder and exercise) and found seven relevant articles. In another Medline search from 1966 to July 


\section{What is already known}

- Not many studies on exercise induced haematuria have been published. However, this problem is not rare. The most general reasons for exercise induced haematuria are briefly reviewed.

\section{What this study adds}

- We describe a case of haematuria which was probably due to the blood vessels in the posterior wall of the bladder. This cause of haematuria has not been reported before.

2003 (keywords: haematuria and bladder and vessels) we found 20 articles. However, no similar cases were described. Only in a review article by Abarbanel et $a l^{11}$ was it mentioned that one reason for sport related haematuria can be a bladder injury caused by the repeated impact of the posterior bladder wall against the bladder base, which can cause vascular lesions and haematuria.

In this study, the patient took $100 \mathrm{mg}$ aspirin a day before the first gross haematuria. According to the literature, the use of non-steroidal anti-inflammatory drugs such as aspirin can induce haematuria. ${ }^{12}$ However, in a later study on dipstick haematuria, no association was found between the presence of haematuria and intake of non-steroidal anti-inflammatory drugs. ${ }^{13}$ The use of aspirin in this case was not the reason for the haematuria, because the symptoms continued after the medication was stopped.

In our case, the first and second macroscopic haematuria period were exercise induced. According to the literature there are several reasons for sport related haematuria: foot strike haemolysis, renal ischaemia, hypoxic damage of the kidney, the release of a haemolysing factor in the bladder, renal trauma, dehydration, increased circulation rate, myoglobinuria, the peroxidation of red blood cells, and nutcracker syndrome. ${ }^{14}{ }^{15}$ Some studies have indicated that exercise associated haematuria resolves in 24-48 hours. ${ }^{1}$ In urine samples taken from 122 long distance runners after exercise, abnormalities were found on microscopic examination in $95 \%{ }^{16}$ Proteinuria, alone or with microscopic haematuria, was commonly found. However, macroscopic haematuria was a rare occurrence. The abnormal urinary findings disappeared in all cases within 24-36 hours. ${ }^{16}$

The reason for recurrent exercise induced haematuria can also be a bladder carcinoma. ${ }^{17}$ This should be kept in mind, and a urological evaluation is always necessary if the haematuria is recurrent, as well as in older athletes.

If there are diagnostic problems, the red blood cells in the urine should be examined to determine if they are dysmorphic or isomorphic. Dysmorphic red blood cells are an indication of glomerulonephritis, and isomorphic red blood cells are seen when the bleeding is post-renal. ${ }^{4}$ In this case, the morphology of the red cells was not examined. The investigation should have been performed during the second stage of haematuria, because it could have shown whether the bleeding was renal or post-renal. Thus, unnecessary examinations would have been avoided.

\section{Authors' affiliations}

P Lüthie, Department of Surgery, Regional Hospital, Kuusankoski, Finland

I Nurmi, Department of General Practice and Primary Health Care, University of Helsinki, Helsinki, Finland

Correspondence to: Dr Lüthje, Department of Surgery, Regional Hospital, Fin-45750 Kuusankoski, Finland; peter.luthje@kymshp.fi

Accepted 6 January 2004

\section{REFERENCES}

1 Siegel AJ, Hennekens $\mathrm{CH}$, Solomon HS, et al. Exercise-related hematuria. Findings in a group of marathon runners. JAMA 1979;242:391-2.

2 Reid RI, Hosking DH, Ramsey EW. Haematuria following a marathon run: source and significance. $\mathrm{Br} J$ Urol 1987;59:133-6.

3 Kallmeyer JC, Miller NM. Urinary changes in ultra long-distance marathon runners. Nephron 1993;64:119-21.

4 Blacklock NJ. Bladder trauma in the long-distance runner: 10000 metres haematuria. Br J Urol 1977;49:129-32.

5 Fassett R. Exercise haematuria. Aust Fam Phys 1984;13:518-19.

6 Mebust WK, Holtgrewe HL, Cockett ATK, et al. Transurethral prostatectomy: immediate and postoperative complications. A cooperative study of 13 participating institutions evaluating 3,885 patients. J Urol 1989;141:243-7.

7 Foley SJ, Bailey DM. Microvessel density in prostatic hyperplasia. BJU Int 2000;85:70-3.

8 Foley SJ, Soloman LZ, Wedderburn AW, et al. A prospective study of the natural history of hematuria associated with benign prostatic hyperplasia and the effect of finasteride. J Urol 2000;163:496-8.

9 Hochberg DA, Basillotte JB, Armenakas NO, et al. Decreased suburethral prostatic microvessel density in finasteride treated prostates: a possible mechanism for reduced bleeding in benign prostatic hyperplasia. J Urol 2002; 167:1731-3.

10 Pareek G, Shevchuk M, Armenakas NO, et al. The effect of finasteride on the expression of vascular endothelial growth factor and microvessel density: a possible mechanism for decreased prostatic bleeding in treated patients. JUrol 2003; 169:20-30

11 Abarbanel J, Benet AE, Lask D, et al. Sports hematuria. J Urol 1990;143:887-90.

12 Kraus SE, Siroky MB, Babayan RK, et al. Hematuria and the use of nonsteroidal anti- inflammatory drugs. J Urol 1988;132:288-90.

13 Britton JP, Dowell AC, Whelan P. Dipstick haematuria: its association with smoking and nonsteroidal anti-inflammatory drugs. J $R$ Soc Med 1990:83:149-51.

14 Jones GR, Newhouse I. Sport-related hematuria: a review. Clin J Sport Med 1997;7:119-25.

15 Mercieri A, Mercieri M, Armanini M, et al. Exertional haematuria. Lancet 2002;359:1402.

16 Gilli P, De Paoli Vitali E, Tataranni G, et al. Exercise-induced urinary abnormalities in long-distance running. Int J Sports Med 1984;5:237-40.

17 Mueller EJ, Thompson IM. Bladder carcinoma presenting as exercise-induced hematuria. Postgrad Med 1988;84:173-6. 